\title{
An Analysis of the Proximity Based Polarisation of the Hospital Network of Moldavia's Counties
}

\author{
Andra-Cosmina Albulescu ${ }^{1, \bowtie}$, Daniela Larion ${ }^{1}$ \\ ${ }^{1}$ Alexandru Ioan Cuza University of Iasi, Department of Geography, Romania
}

\begin{abstract}
Since 1990, the deficiencies of the widely criticised health care system of Romania have been analysed from economic, political and management related points of view, but the territorial dimension of this system was often neglected. Identifying and understanding the shaping role of the spatial dimension are the prerequisites of any effective and compelling implementation of change. This paper aims to analyse the hospital network in Moldavia's counties from the geographic proximity based influence point of view. The polarisation areas of territorial, emergency and specialised (pneumology and phthisiology, psychiatric) hospitals are generated as Thiessen proximal polygons. These geometric constructions help to determinate the locations that are the closest to a particular hospital, which proves to be useful in medical emergency situations, but also when distance becomes an important restrictive factor - as in the case of vulnerable population with limited financial resources, scarce mobility opportunities or constraints imposed by age. The hospital network may be considered the backbone of the medical system and its spatial distribution should be taken into account as an important shaping factor. This paper offers a regional approach of this matter, which can be used for planning bottom-up improvement strategies.
\end{abstract}

Keywords: hospital network of Moldavia, medical services of Moldavia, health care system of Romania, Thiessen polygons, Medical Geography.

\section{Introduction}

The health care system is one of the most important pillars that a country stands on, which means that its deficiencies may negatively affect the development process. Romania's medical system has been widely criticised by public opinion, medical

\footnotetext{
CORRESPONDENCE:

$\triangle$ Alexandru Ioan Cuza University of Iași, Department of Geography, Bd.

Carol I 20A, 700505, Iași, Romania.

@ cosminaalbulescu@yahoo.com (A.-C. A.), danielalarion@yahoo.co.uk (D. L.)
} 
personnel, interested investors and politicians. Nevertheless, the underdevelopment of this system is not a result of a singular event, but more of a perpetual convergence of economic, political and management related factors.

The transition between the highly centralised health care system that existed before 1990 and the more decentralised medical system of present times led to instabilities that are only partially extinct today. The impediments that the medical reforms have encountered include "legislative inconsistency, insufficient and misplaced finance, increasing health care costs". (Dumitrache et al., 2008) While it appears that the issues that hindered the development of the medical system of Romania in the past reiterate, new unfavourable factors like the discordance between the public and the private medical sectors and the improper regulation and coordination of the subordinate institutions emerge. (Dumitrache et al., 2016; Farcasanu, 2010)

One of the most significant problems faced by the health care system of Romania is represented by underfunding. Romania ranks among the last EU countries in terms of health expenditure, in 2014 spending only $5.4 \%$ of its GDP on the health system. Also, in 1995-2013, although Romania's health expenditure as share of GDP increased, it was still surpassed by comparator countries such as Bulgaria, the Czech Republic, Hungary, Poland and Slovakia. (Vlădescu et al., 2016) Additionally, the medical system of Romania has to deal with the migration of highly trained medical professionals, a low number of permanent health care units, a low ratio between the family doctors and the population of rural areas, informal payments, corruption, the focus on treatment rather than prevention, the sanitary migration and the widespread perception of the health system as an underperforming one. (Dumitrache et al., 2008; Ciutan et al., 2009; Farcasanu, 2010; Jankauskiene et al., 2011)

Identifying and understanding the problems of the health care system are prerequisites for solving these matters. While studies about the economic factors (Vlădescu et al., 2016; Suciu et al., 2012) and the cultural and social factors (Farcasanu, 2010; Jankauskiene et al., 2011; Karanikolos et al., 2011) that may be held accountable for the current underperformance status of Romania's medical system have been conducted over the years, the territorial dimension of this system and its role in shaping the reality have been taken into account only recently. (Ciutan et al., 2009; Dragomirișteanu, 2010; Eva et al., 2015; Dumitrache et al., 2016) An akin study that focuses on the territorial disparities between the spatial distribution of the medical resources and the population that may need them, emphasising the unevenly distributed medical units and medical personnel, the elderly population and the distribution of the economic vulnerable population, points out that Romania presents a "divided landscape of care". (Dumitrache et al., 2016) 
The applications that consider the territorial dimension of the health care system as an important factor in its analysis tend to be focused on the entire territory of Romania, providing only an overview of the situation. The variability of the local conditions that influence the medical system and their dynamics call for a regional and local scale approach. Such approaches prove to offer highly relevant information about the situation regarding the degree to which the health care services are capable of meeting the needs of the population. (Ursulica, 2016) Also, recent regional studies that aim to analyse the spatial accessibility to medical care confirm that this type of approaches are more relevant and useful in the endeavour of identifying the implications of the territorial dimensions of the health care system. (Mareci, 2008; Eva et al., 2015)

The more targeted the approach is, the better are the results in terms of pertinence and practicality. The utilisation of GIS based methods may be considered a stepping stone in the process of obtaining such results because they allow the integration of various factors of influence, like the distribution of natural barriers and of the road network or the proportion of people likely to use public transport in order to reach medical services. (Tanser et al., 2006)

This paper aims to analyse the polarisation of the medical services provided by the hospital network in Moldavia region from a geographic proximity based influence point of view. Today, this type of proximity is not of vital importance for economic development, technological innovations or learning endeavours, but it remains important when the physical presence of people is a precondition of the activity of interest. (Boschma, 2005)

A polarisation analysis should include a multitude of factors such as information and knowledge, indirect financial costs, culture related factors, and personal preferences. (Oliver et al., 2004) Among them, geographic proximity is listed as a key factor, as there are situations that prove that distances are relevant concerning the polarisation of the medical services. An eloquent example is the one of vulnerable population with limited financial resources and limited mobility opportunities, for whom the proximity to a medical service may determine the ability to benefit from it. Also, proximity is important for most of the potential patients due to the emergency status of their health problem or because of the fact that they tend to seek the closest hospital and eventually be transferred to a more suitable one after they had been examined and provided with immediate medical assistance.

The relevance of the geographic proximity in assessing the polarisation or access to the medical services is proved by the continuity of studies that focus on the role the geographic proximity plays as a determinant factor regarding both specialised health care provision, such as coronary artery bypass graft, and general health care provision. (Ben-Shlomo et al., 1995; Cordasco et al., 2011) 


\section{An overview of Moldavia's hospital network}

The available data regarding the medical system of Moldavia show contrasting aspects. According to the 2014 list of public hospitals provided by the Ministry of Health of Romania under Open Government Licence, there are 58 public hospitals (with or without clinical sections) in the eight counties of the spatial entity of Moldavia, excluding the ones destined for the population involved in military or railway transport services and also the ones associated with penitentiaries or that implemented safety measures.

The county with the largest number of hospitals is Iași (15 hospitals), while the county with the lowest number of hospitals is Vaslui (14 hospitals). Each of Moldavia's counties has one county hospital and one or more municipal hospitals, but not all the counties benefit from the services of city or community hospitals. (Table 1).

Out of the total of 58 hospitals, 23 of them are specialised hospitals: emergency hospitals (that are also listed as county or municipal hospitals), emergency hospitals for children, clinic hospitals specialised in renal diseases, pneumology and phthisiology hospitals, psychiatric hospitals, hospitals for infectious diseases, recovery hospitals and obstetrics-gynaecology hospitals. Most of them are located in Iași (9 hospitals) and Galați counties (5 hospitals). In addition, the medical system in Moldavia includes 5 medical units represented by institutes (specialised in oncology and cardiovascular diseases), sanatoria, neuropsychiatric sanatoria and tuberculosis observation sanatoria for children. These are located in Iași ( 3 medical units), Botoșani (1 medical unit) and Neamț (1 medical unit).

Table 1. The components of the hospital network of Moldavia's counties in 2014 (Data source: the Ministry of Health of Romania)

\begin{tabular}{cccccccc}
\hline Counties & Hospitals & $\begin{array}{c}\text { County } \\
\text { hospitals }\end{array}$ & $\begin{array}{c}\text { Municipal } \\
\text { hospitals }\end{array}$ & $\begin{array}{c}\text { City } \\
\text { hospitals }\end{array}$ & $\begin{array}{c}\text { Community } \\
\text { hospitals } \\
\text { (rural) }\end{array}$ & $\begin{array}{c}\text { Specialised } \\
\text { hospitals }\end{array}$ & $\begin{array}{c}\text { Other types } \\
\text { of medical } \\
\text { units }\end{array}$ \\
\hline Bacău & 6 & 1 & 2 & 2 & 0 & 1 & 0 \\
Botoșani & 5 & 1 & 1 & 0 & 0 & 2 & 1 \\
Galați & 8 & 1 & 1 & 1 & 0 & 5 & 0 \\
Iași & 15 & 1 & 1 & 1 & 0 & 9 & 3 \\
Neamț & 6 & 1 & 1 & 1 & 0 & 2 & 1 \\
Suceava & 9 & 1 & 4 & 2 & 0 & 2 & 0 \\
Vaslui & 4 & 1 & 2 & 0 & 0 & 1 & 0 \\
Vrancea & 5 & 1 & 1 & 1 & 1 & 1 & 0 \\
\hline Moldavia & 58 & 8 & 13 & 8 & 1 & 23 & 5 \\
region & & & & & &
\end{tabular}




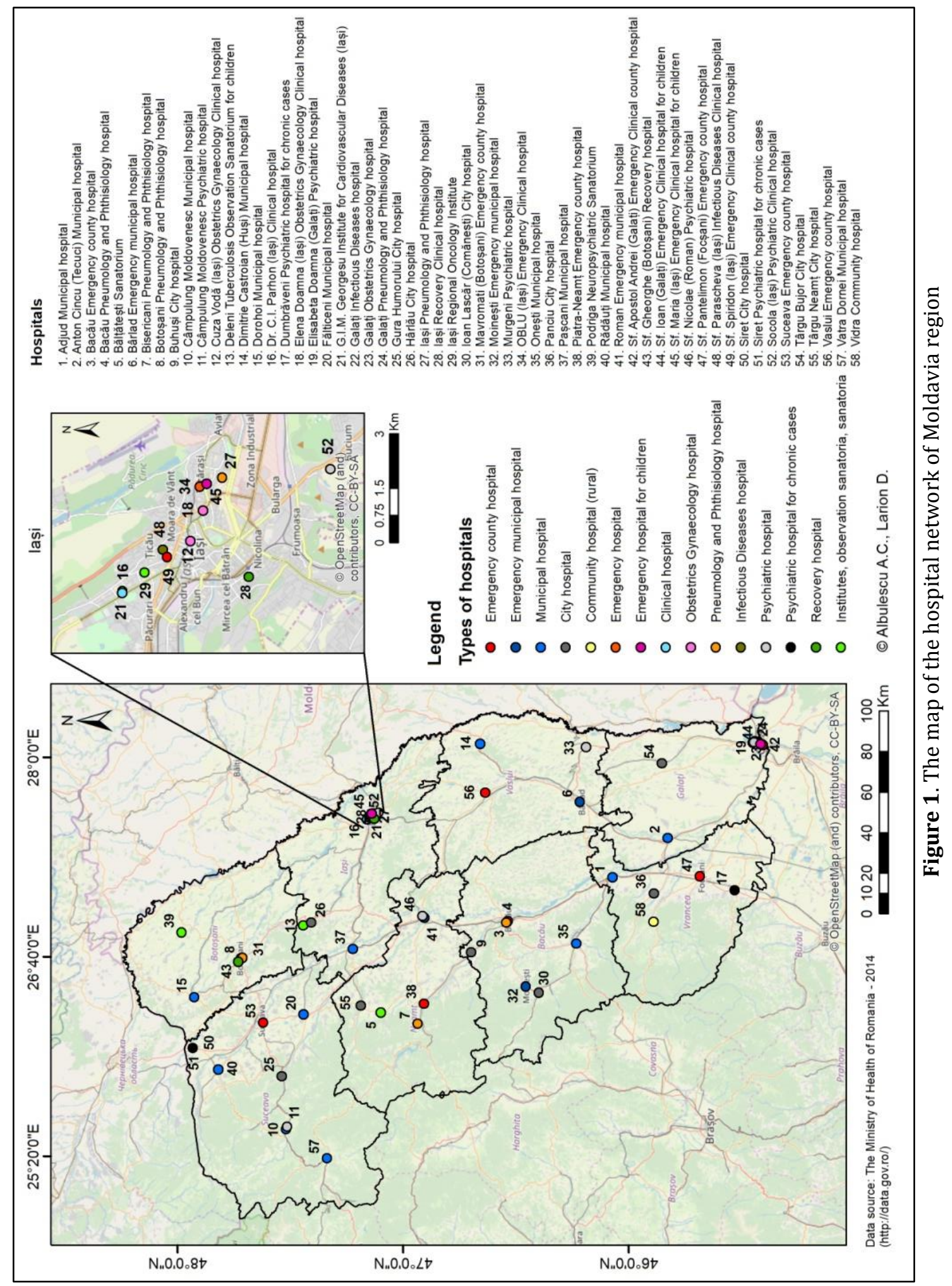


The map of the hospital network of Moldavia (Figure 1) indicates a tendency for hospital clustering in the cities that fulfil administrative functions at county level. The most influential clusters are located in cities like Iași and Galați, while smaller clusters may be identified in Bacău and Botoșani cities. In the case of Galați County, the distribution of the hospitals seems to be problematic, as most of the hospitals are clustering in the south of the territory and the northern areas of the county have to depend on municipal and city hospitals. Other territorial discrepancies may be observed in Suceava, Neamț and Vrancea counties, where most of the hospitals are located in the eastern parts of the territories. On the other hand, the more balanced distribution of the hospitals in Vaslui County does not necessarily suggest a better provision of medical services because of the low number of such medical units.

The human component of the medical system consists of medical personnel with tertiary education (physicians, dentists, pharmaceutical chemists), ancillary medical staff (medical, pharmacy and laboratory assistants, medical nurses and officiants, sanitary technicians, midwives and other categories of medical staff with equivalent upper secondary level of education) and auxiliary staff. (The National Institute of Statistics). Comprising the data provided by the National Institute of Statistics (INSSE) for the year of 2016, Table 2 indicates that in Moldavia the percentage of medical personnel reported to the total of Romania is higher than $15 \%$ for physicians, family doctors, dentists, pharmaceutical chemists and ancillary medical staff. This suggests an overall relatively stable provision of medical staff, but at county level the situation is not optimal.

The number of physicians in Moldavia's counties (8784) in 2016 represents $15.32 \%$ of the total number of physicians in Romania. However, less than $1 \%$ of this highly trained medical staff is available in Vrancea and Vaslui counties, while the specific percentage for Iași County represents almost a third (5.82\%) of the one attributed to the whole region of Moldavia. There are also discrepancies regarding the family doctors, Vrancea, Vaslui and Botoșani counties comprising each less than $1.5 \%$ of the total number of family doctors. Moreover, the percentage of dentists available in Botoșani and Vaslui counties is subunitary, while the one in Iași is very high $(7.73 \%)$. The data point out that the counties with a deficit of medical personnel are Vaslui, Botoșani and Vrancea and that the best provision of medical staff is attributed to Iași, Suceava, Bacău and Galați counties.

The territorial disparities that exist between the counties of Moldavia are curbed when analysing the indicators referring to the specific types of medical personnel/1000 inhabitants in 2016. (Table 3) The number of physicians/1000 inhabitants in Moldavia (2.13) is lower than the national one (2.89) and all the indicators specific to the counties of interest, except the one of Iași County (4.23), are lower than both the regional and the national level. Vaslui County presents the 
lowest number of physicians/1000 inhabitants (1.37), meaning that each physician has to take care of more than 1000 inhabitants.

Table 2. The medical staff of Moldavia's counties in 2016 (Data source: the National Institute of Statistics)

\begin{tabular}{|c|c|c|c|c|c|c|c|c|c|c|}
\hline \multirow{2}{*}{ County } & \multicolumn{2}{|c|}{ Physicians } & \multicolumn{2}{|c|}{$\begin{array}{l}\text { Family } \\
\text { doctors }\end{array}$} & \multicolumn{2}{|c|}{ Dentists } & \multicolumn{2}{|c|}{$\begin{array}{l}\text { Pharmaceutical } \\
\text { chemists }\end{array}$} & \multicolumn{2}{|c|}{$\begin{array}{l}\text { Ancillary medical } \\
\text { staff }\end{array}$} \\
\hline & No. & $\begin{array}{l}\% \text { of } \\
\text { total }\end{array}$ & No. & $\begin{array}{l}\% \text { of } \\
\text { total }\end{array}$ & No. & $\begin{array}{l}\% \text { of } \\
\text { total }\end{array}$ & No. & $\begin{array}{l}\% \text { of } \\
\text { total }\end{array}$ & No. & $\begin{array}{l}\% \text { of } \\
\text { total }\end{array}$ \\
\hline Bacău & 1086 & 1.89 & 290 & 2.35 & 321 & 1.95 & 281 & 1.63 & 3639 & 2.65 \\
\hline Botoșani & 610 & 1.06 & 183 & 1.48 & 147 & 0.89 & 190 & 1.10 & 2447 & 1.78 \\
\hline Galați & 938 & 1.63 & 281 & 2.27 & 333 & 2.02 & 207 & 1.20 & 3329 & 2.42 \\
\hline Iași & 3339 & 5.82 & 459 & 3.72 & 1272 & 7.73 & 1247 & 7.25 & 6051 & 4.40 \\
\hline Neamț & 811 & 1.41 & 256 & 2.07 & 280 & 1.70 & 292 & 1.70 & 3062 & 2.23 \\
\hline Suceava & 942 & 1.64 & 321 & 2.60 & 432 & 2.62 & 433 & 2.52 & 4005 & 2.91 \\
\hline Vaslui & 531 & 0.92 & 180 & 1.45 & 150 & 0.91 & 165 & 0.96 & 2224 & 1.62 \\
\hline Vrancea & 527 & 0.92 & 165 & 1.33 & 176 & 1.07 & 117 & 0.68 & 1914 & 1.39 \\
\hline $\begin{array}{l}\text { Moldavia } \\
\text { region }\end{array}$ & 8784 & 15.32 & 2135 & 17.31 & 3111 & $\begin{array}{c}18.9 \\
2\end{array}$ & 2932 & 17.06 & 26671 & 19.43 \\
\hline
\end{tabular}

Table 3. The proportion of physicians, family doctors, dentists /1000 inhabitants of Moldavia's counties in 2016 (Data source: the National Institute of Statistics)

\begin{tabular}{ccccc}
\hline County & Population & $\begin{array}{c}\text { Physicians/1000 } \\
\text { inhabitants }\end{array}$ & $\begin{array}{c}\text { Family doctors/1000 } \\
\text { inhabitants }\end{array}$ & $\begin{array}{c}\text { Dentists/1000 } \\
\text { inhabitants }\end{array}$ \\
\hline Bacău & 600549 & 1.80 & 0.48 & 0.53 \\
Botoșani & 394625 & 1.54 & 0.46 & 0.37 \\
Galați & 520058 & 1.80 & 0.54 & 0.64 \\
Iași & 788659 & 4.23 & 0.58 & 1.61 \\
Neamț & 455643 & 1.78 & 0.56 & 0.61 \\
Suceava & 629733 & 1.49 & 0.51 & 0.68 \\
Vaslui & 387525 & 1.37 & 0.46 & 0.38 \\
Vrancea & 330937 & 1.59 & 0.49 & 0.53 \\
\hline Moldavia & 4107729 & 2.13 & 0.51 & 0.75 \\
region & & 2.89 & 0.62 & 0.83 \\
\hline Romania & 19760585 & & & \\
\hline
\end{tabular}

Regarding the family doctors to 1000 inhabitants ratio, the national level is of 0.62 family doctors for every 1000 inhabitants and the regional one is of 0.51 family doctors for every 1000 inhabitants. At county level, these values range from 0.46 family doctors/1000 inhabitants in Vaslui and Botoșani to 0.58 family doctors/1000 inhabitants in Iași, suggesting a narrower gap between these values and the national or regional ones.

The number of dentists/1000 inhabitants is 0.83 for whole population of Romania and 0.75 for the population in Moldavia's counties. Botoșani (0.37 
dentists/1000 inhabitants) and Vaslui (0.38 dentists/1000 inhabitants) counties are characterised by a shortage of dentists, as each dentist in these counties has to serve over 2000 inhabitants. On the other hand, in Iași County there are almost 2 dentists for every 1000 inhabitants, the number of 1.61 dentists/1000 inhabitants being higher than the national and regional values of this indicator.

These data suggest that the physicians, family doctors and dentists working in public and private medical units have to serve a high number of people in many of Moldavia's counties. A prolonged situation of this kind may lead to an overburdened local medical system. Moreover, the shortage of medical staff in some of these counties combined with a lack of trust in the quality of the local medical services and the attractiveness of the nationally recognised medical centre of Iași are considered causes of the "sanitary migration". This phenomenon is aforementioned at a national level and also concerns other influential medical centres. (Dumitrache et al., 2008)

\section{Methods}

In order to analyse the spatial distribution of the hospitals in Moldavia and to obtain a better understanding of the areas they polarise from a geographic proximity point of view, Thiessen polygons (also known as Voronoi diagrams) are used as a basis for mapping. These help to differentiate between the areas that certain elements, in this case the different types of hospitals, extend their influence to in terms of closeness.

Thiessen polygons are geometric constructions generated around a set of points that are called "generators" or "generator points" by assigning all the points in plane to the closest generator point. Mathematically, for "a given set of distinct, isolated $n$ points, $P=\left\{p_{1}, \ldots, p_{n}\right\}$, in a Euclidean plane, $R$, a Voronoi diagram is constructed by assigning all locations in $R$ to the closest member of $P^{\prime \prime}$. (Yamada, 2016) The totality of the polygons is exhaustive in plane and polygons do not overlap. If a point in plan is equidistant to two or more generator points, that point is encompassed as part of the boundary between the polygons. (Yamada, 2016)

Thiessen polygons are also called Voronoi diagrams, after the Ukrainian mathematician who contributed to the development of the concept. The term "Thiessen polygon" comes from the application conducted by the American meteorologist A.H. Thiessen in order to improve the estimation of regional rainfall averages. (Thiessen, 1911) However, this is an interdisciplinary concept, meaning that it was developed in many fields and in different contexts. It is used in Computational geometry, Cryptography, Astronomy, Geography, Geology, Meteorology, Ecology, Urban and Regional Planning, Physics, Robotics, Biology, Epidemiology, Marketing, Anthropology, Linguistics. (Yamada, 2016; Dobrin, 2005)

In Geography, the term "Thiessen polygon" is preferred for the twodimensional applications, but the concept may be extended to multi-dimensional 
Euclidean space. (Yamada, 2016) In this field, Thiessen polygons may be regarded as polarisation areas of the generator points and prove to be useful for identifying space related problems.

The use of these geometric constructions in the endeavour to obtain a better understanding of the implications of the hospital network's distribution consider as prerequisites the assumptions that all the hospitals provide the same kind of services and that a patient would choose the most accessible hospital in terms of distance. Although these assumptions are not of absolute veracity, a distinction between the types of the hospitals may solve the issues related to the first prerequisite. This means that separate analyses that take into account hospitals that offer the same types of services prove to be reliable. Also, the assumption that a possible patient would choose the closest hospital is valid in many cases, as emergency situations call for immediate action and practical solutions. In this case, the patient may choose the closest hospital for immediate medical examination and assistance, eventually being transferred to a specialised or better equipped hospital afterwards.

It is important to point out that proximity is a "fashionable" term that may be used in a variety of contexts: cognitive, organisational, social, institutional and geographic proximity. (Torre et al., 2000; Boschma, 2005) In this paper, the term refers to geographic proximity, meaning the "spatial distance between actors, both in absolute and relative meaning". (Boschma, 2005)

For the purpose of this application, the generator points are represented by different types of hospitals, like the territorial ones (county, municipal and city hospitals), the emergency hospitals, the pneumology and phthisiology, and the psychiatric hospitals. The data regarding the aforementioned hospitals are provided by the Ministry of Health of Romania under Open Government Licence and correspond to the year of 2014. The hospitals that serve military of railway transport personnel, as well as the ones associated with penitentiaries or safety measures are excluded, as they are not supposed to provide medical services to the general population. Regarding the territorial hospitals, the Thiessen polygons are used complementarily with a buffer ring based map that shows the Euclidean distances of $25 \mathrm{~km}, 50 \mathrm{~km}$ and $75 \mathrm{~km}$ around the selected medical units.

The Thiessen polygons that were generated around the selected types of generator points play the role of proximal polygons, showing the areas that are polarised by those hospitals from the point of view of distance. The computation algorithm of these polygons is set to fit the geometric constructions within the boundaries of Moldavia region, which means that the proximity influence of some of the hospitals may extend to other counties outside the region of interest. The areas of the resulting polygons are computed and grouped in relevant classes that indicate the dimensions of the territories provided with medical services by these hospitals. Also, the order numbers of the polygons are associated with their dimensions, the 
first polygon being the most extensive one.

These choropleth maps reveal hypothetical situations, as the influence of some hospitals extends beyond the boundaries of the associated polygons. Other factors like the financial possibilities of the population, the characteristics of the transport infrastructure and of the traffic and the regulations specific to the hospitals should be taken into consideration in evaluating the extension of the influence of a medical unit.

Yet the situations portrayed by these maps are not to be neglected, as they are relevant for the vulnerable population with limited financial possibilities, with constraints determined by age or even by a poor health condition. For this population groups, the geographic proximity criterion becomes the most important one, as the financial cost is dependent on it (Mareci, 2008). Moreover, in case of emergency even the less vulnerable segments of population would choose the closest hospital for immediate medical assistance. These arguments demonstrate the usefulness of the results, as the betterment of the hospital network should focus on the issues faced by the disadvantaged population.

\section{Results}

From a territorial point of view, the hospitals in Romania are divided in regional, county and local hospitals (municipal, city and community hospitals). (Law no. 95/2006) As there are no regional hospitals in Moldavia and the influence of the under-equipped community hospital in Vrancea County is of little importance the analysis takes into account 29 county, municipal and city hospitals. Some of these are also emergency hospitals and/or clinical hospitals. County hospitals have complex structures, being equipped with medical units that ensure the provision of emergency and specialised medical assistance. Also, the severe cases that cannot be solved at a local level are assigned to county hospitals. Concurrently, the local hospitals ensure the provision of medical services at municipal or city level. These hospitals are listed as general hospitals that usually comprise two of the four main medical specialisations (internal medicine, paediatrics, obstetrics-gynaecology, general surgery). (Law no. 95/2006)

The Thiessen proximal polygons determined by the territorial hospitals reveal a balanced distribution of the medical units of this kind, the most extensive polygons with areas of $2000.1-2500 \mathrm{~km}^{2}$ being located in the eastern and western parts of the region. (Figure 2) The distortions represented by the small area of influence associated with the county hospital of Suceava is determined by the fact that this location is close to the county hospital of Botoșani. 


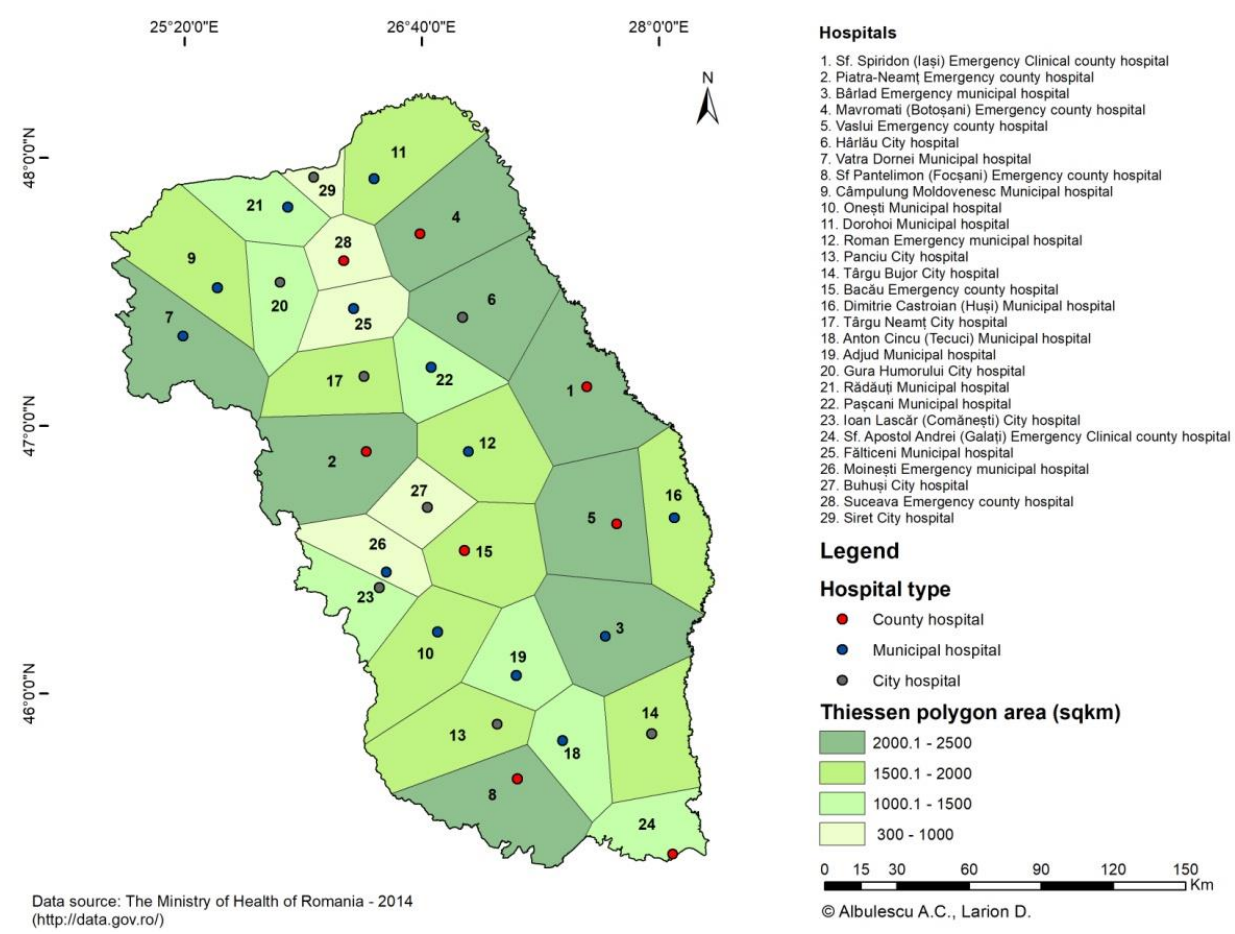

Figure 1. The Thiessen polygons determined by the territorial hospitals of Moldavia's counties

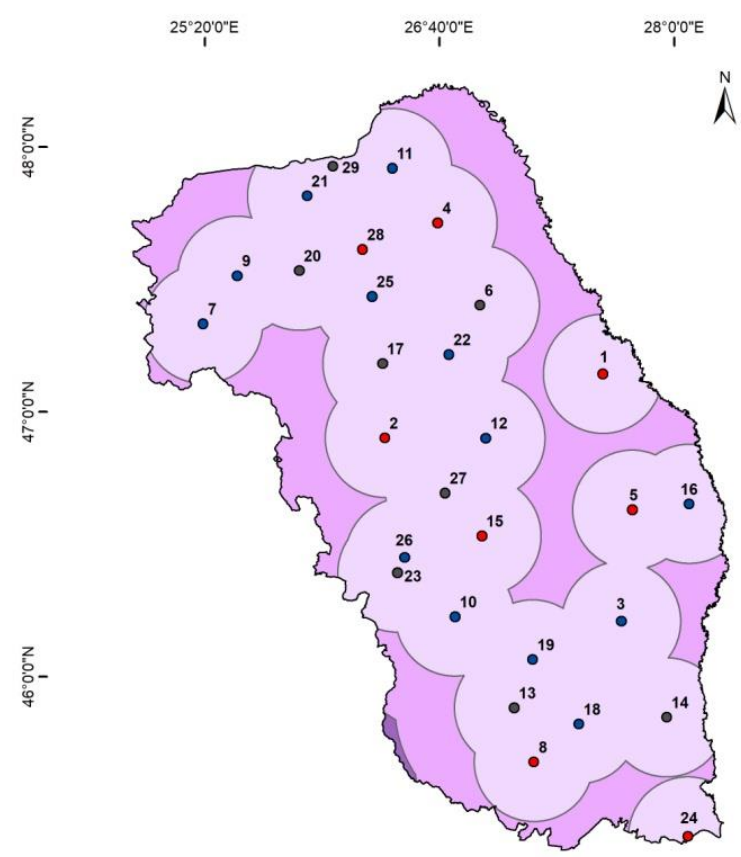

Data source: The Ministry of Health of Romania - 2014 (http://data.gov.ro/)

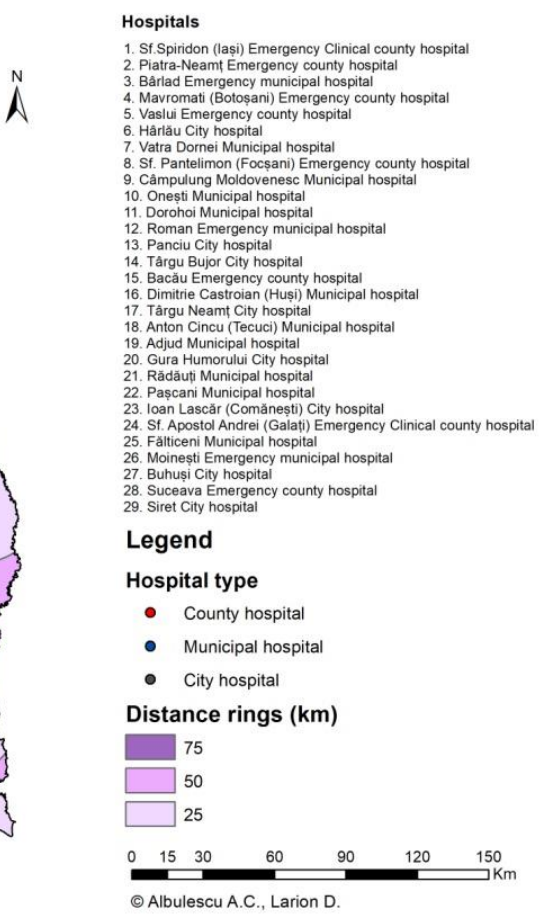

Figure 2. The distance rings generated around the territorial hospitals of Moldavia's counties 
The relatively even distribution of the territorial types of hospitals in Moldavia is confirmed by the map regarding the distance rings generated around the elements of interest. (Figure 3) This map indicates that the distances between most of the hospitals are smaller than $50 \mathrm{~km}$. There is only a narrow territory that is located between 50 and $75 \mathrm{~km}$ away from a hospital, in the south-western part of the region, in Vrancea County.

This spatial distribution suggests that the territorial hospitals of Moldavia are characterised by complementarity, but it does not imply that there is also a functional complementarity at the network level. In order to assess the existence or the absence of such a particularity, independent analyses focusing on specialised hospitals are conducted.

An emergency hospital should be highly accessible as it aims to serve large territories. It is equipped with a complex structure of medical specialisations, adequate medical equipment, specialised medical professionals and also comprises an emergency structure that may possess a mobile emergency reanimation service and medical assisted transportation. (Law no. 95/2006) The emergency hospital network of Moldavia is not as balanced as the one formed by the territorial hospitals (which also include county or municipal emergency hospitals). (Figure 4) Two clusters of hospitals providing medical emergency services may be noticed, one in Iași and the other in Galați, as opposed to the deficit of such medical units in the north of Moldavia, where the only medical emergency services are the ones provided by the county hospitals of Suceava and Botoșani. The proximal polygon generated around Suceava County hospital covers an area of over $8000 \mathrm{~km}^{2}$, meaning that a very high number of medical emergency cases is assigned to this hospital Another shortage of medical emergency services characterises Vrancea County.

Moreover, the territorial distribution of specialised medical services determines problems related to proximity based accessibility. While some of the county, municipal and city hospitals may comprise medical sections of obstetricsgynaecology or paediatrics, there are specialised medical units that provide certain types of medical services that are not available in territorial hospitals. Among these are the pneumology and phthisiology or psychiatric hospitals that have to provide medical services for large areas.

An eloquent example is the one of the 5 pneumology and phthisiology hospitals in Moldavia's counties. The Thiessen polygons generated around these medical units cover over $6000 \mathrm{~km}^{2}$, the most extensive one covering an area of over $12000 \mathrm{~km}^{2}$ and being generated around Bacău pneumology and phthisiology hospital. It appears that central southern parts of the region are the most disadvantaged ones in terms of pneumology and phthisiology related medical services supply (Figure 5). 


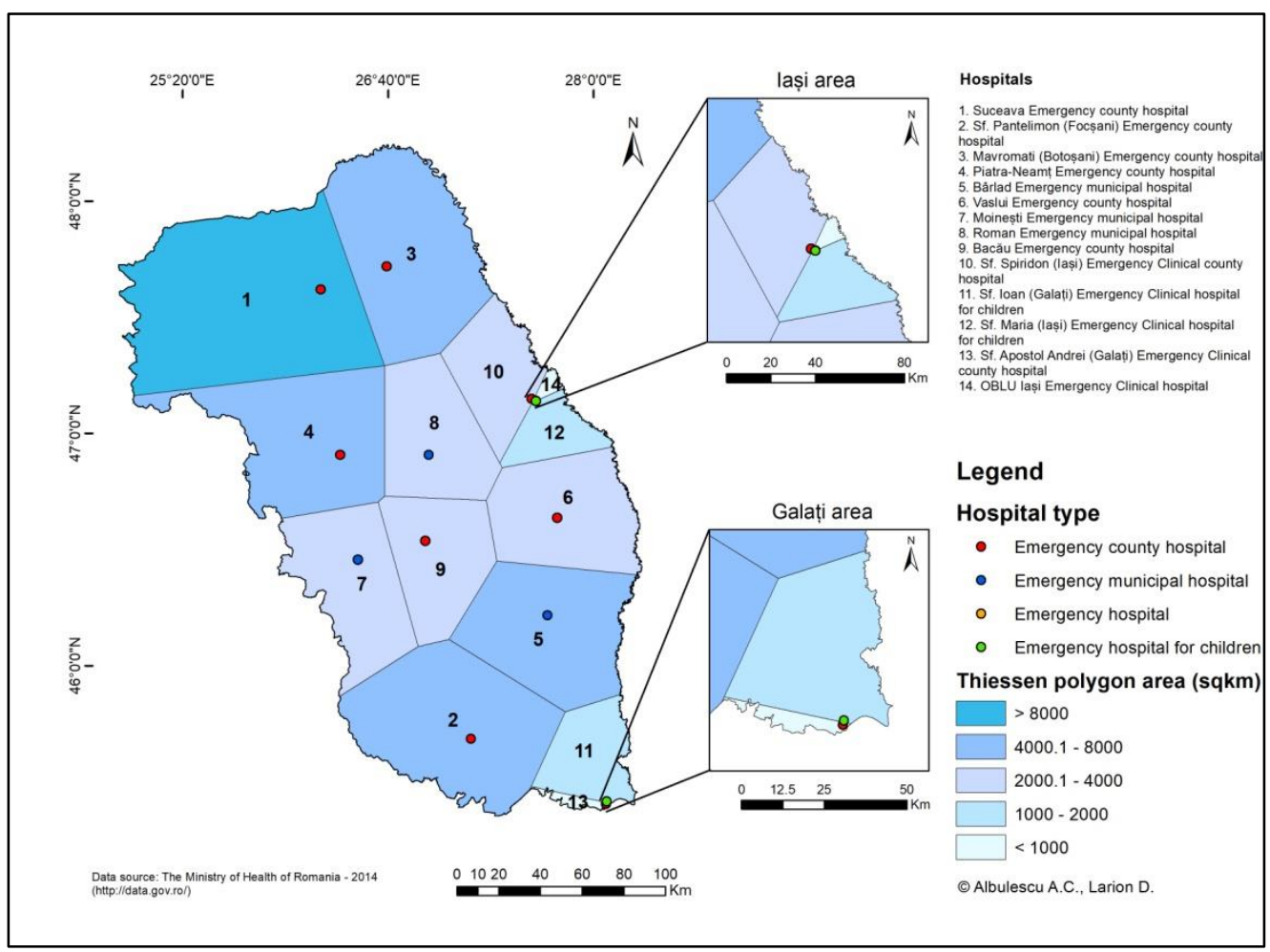

Figure 3. The Thiessen polygons determined by the emergency hospitals of Moldavia's counties

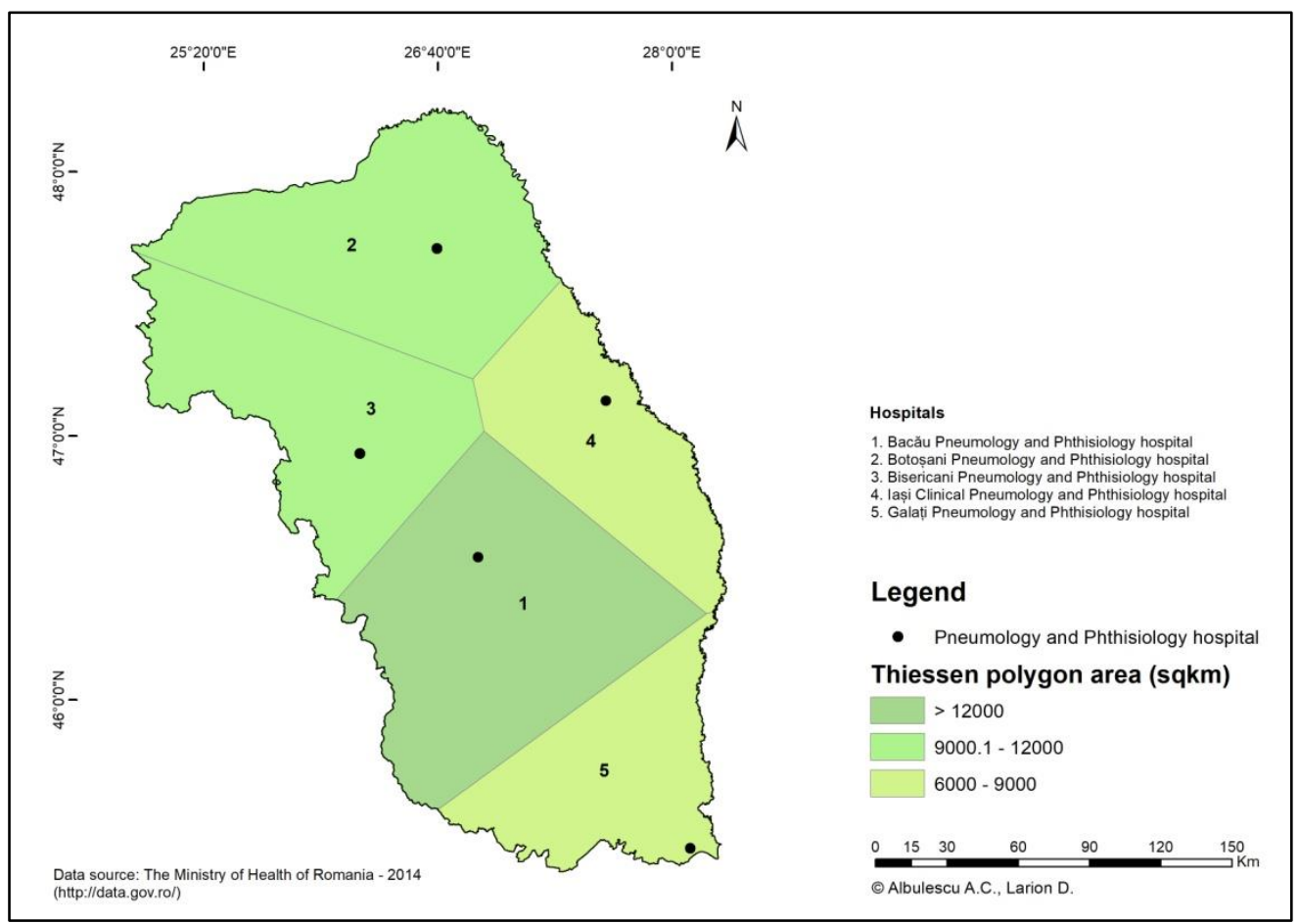

Figure 4. The Thiessen polygons determined by the pneumology and phthisiology hospitals of 


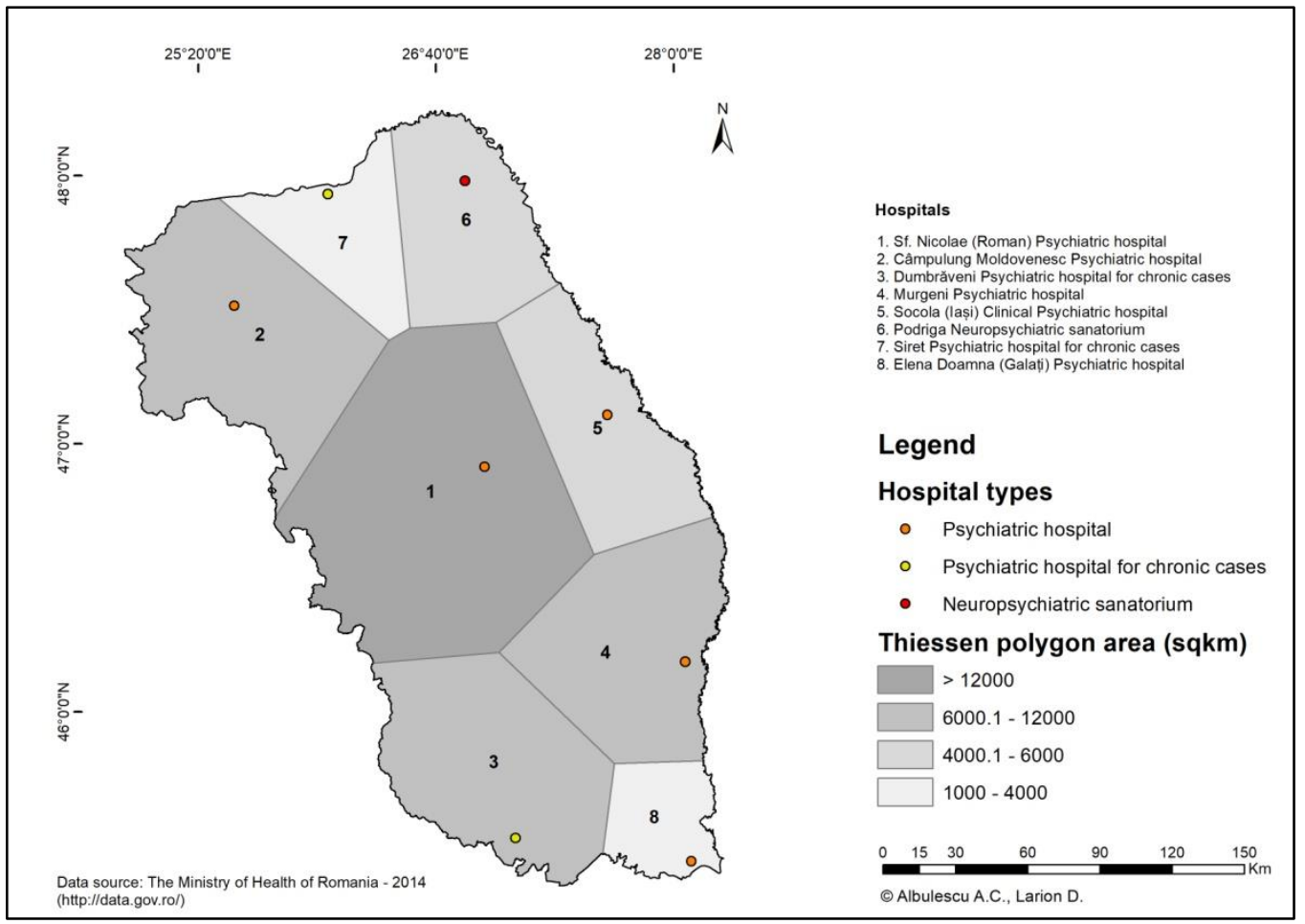

Figure 5. The Thiessen polygons determined by the psychiatric hospitals of Moldavia's counties

Also, the hospitals or sanatoria that provide medical services related to psychiatric diseases are characterised by a problematic distribution. While the northern and the southern parts of Moldavia are better served from the point of view of psychiatric medical services, the centre of the region suffers from a major deficit concerning the services of this kind. (Figure 6) The most extensive Thiessen polygon is the one generated by the Psychiatric hospital in Roman and it has an area larger than $12000 \mathrm{~km}^{2}$. This hospital has to support large areas in both Neamț and Bacău counties from the point of view of psychiatric medical services provision.

\section{Conclusions}

The territorial distribution of the hospital network of Moldavia influences the provision of medical services in a significant way and points out the associated shortcomings. The tendency of hospital clustering in the populous cities fulfilling an administrative function, where medical higher education is available (Iași, Galați) proves to be problematic in the current context of sanitary migration. On the other hand, there are territories that are underserved from the health care services point of 
view (the south-eastern parts of Botoșani County, the western parts of Suceava, Neamț, Vrancea counties).

While the county, municipal and city hospitals are distributed in a way that suggests a high accessibility, the specialised hospitals like the pneumology and phthisiology or psychiatric ones have to provide services for larger areas, risking to be overloaded. Also, the emergency hospitals in Suceava, Vrancea, Botoșani and Neamț counties have to supply emergency medical services for extensive territories. As follows, the complementarity of the county, municipal and city hospitals is not matched by a complementarity at the level of specialised hospitals.

The aforementioned results represent starting points for the strategies that should be designed and implemented in order to improve the hospital network of Moldavia. Their relevance comes to light when considering that national betterment strategies have to be accompanied by effective bottom-up amelioration actions and should focus on the needs of the vulnerable segments of population.

\section{References}

Ben-Shlomo Y., CHATURVEDi N., 1995. Assessing equity in access to health care provision in the UK: does where you live affect your chances of getting a coronary artery bypass graft?, Journal of Epidemiology \& Community Health, 49(2), 200-204

Boschma R., 2005. Proximity and Innovation: A Critical Assessment, Regional Studies, 39(1), 6174

CIUTAN M., CHIRIAC N.D., 2009. The territorial distribution and use of emergency hospitals Romania, 2007 -, Management in Health (1), 66-72

Cordasco K.M., Ponce N.A., GATChell M.S., TrAudT B., EsCARCE J.J., 2011. English language proficiency and geographical proximity to a safety net clinic as a predictor of health care access, Journal of Immigrant and Minority Health, 13(2), 260-267

DOBRIN A., 2005. A review of properties and variations of Voronoi diagrams, Whitman College, http://citeseerx.ist.psu.edu/viewdoc/download?doi=10.1.1.453.9156\&rep=rep1\&type=p df

DRAGOMIRIȘTEANU A., 2010. Reducing inequities in healthcare: a priority for European policies and measures, Management in Health , 14 (3), 14-19

DUMitRACHE L., DUMBRĂVEANU D., 2008. Geographic distribution of sanitary resources in Romania and its consequences on individual and public health, Human Geography, Journal of Studies and Research in Human Geography, 51-60, http://humangeographies. org. ro/articles/22/Dumitrache. pdf

Dumitrache L., Nae M., Dumbraveanu D., Simion G., Suditu B., 2016. Contrasting Clustering in Health Care Provision in Romania: Spatial and Aspatial Limitations, Procedia Environmental Sciences, 32, 290-299

Eva M., IAȚU C., 2015. Modelling spatial accessibility to medical care. Case study of the NorthEastern Region of Romania, Human Geographies: Journal of Studies and Research in Human Geography, 9(2), 151-164 
FARCASANU D.O., 2010. Population perception on corruption, informal payments and introduction of co-payments in the public health system in Romania, Management in Health, 14 (1), 8-13

JANKAUSKIENE D., JANKAUSKAITE I., 2011. Access and quality of health care system by opinion of patients in ten European countries, Management in Health, 15 (3), 31-39

KARANIKOlOS M., MCKeE M., 2011. How well is the Romanian health system performing? - Some progress but still some way to go -, Management in Health , 15 (1), 4-7

Law no. 95/2006. Official Journal of Romania

MARECI A., 2008. The Degree of Accessibility to Health Care-Issues Concerning the North-Eastern Population of Romania, Human Geographies: Journals of Studies and Research in Human Geography, 2(1), 43-53

Oliver A., MOsSialos E., 2004. Equity of access to health care: outlining the foundations for action, Journal of Epidemiology \& Community Health, 58(8), 655-658

SuCIU M.C., STAN C.A., PICIORUȘ L., IMBRIȘCĂ C.I., 2012. The Post-Crisis Healthcare System: Effects of the Economic Crisis in Romania, Theoretical \& Applied Economics, 19 (5), 157 168

TANSER F., GIJSBERTSEN B., HERBST K., 2006. Modelling and understanding primary health care accessibility and utilization in rural South Africa: an exploration using a geographical information system, Social science \& medicine, 63(3), 691-705

THE Ministry OF HeALTH OF ROMANIA (2014). The list of public hospitals of Romania by regions [online] Available at: http://data.gov.ro/dataset/lista-spitalelorpublice/resource/0f076462-a72e-4b2d-ab24-1df4c7f26f2f?inner_span=True [Accessed: 10 Aug. 2018].

The NATIONAL InSTITUTE OF STATISTICS (2016). Medical personnel by categories, forms of property, genders, macroregions, development regions and counties [online] Available

at: http://statistici.insse.ro/shop/index.jsp?page=tempo2\&lang=ro\&context=30 [Accessed: 10 Aug. 2018].

THIESSEN A.H., 1911. Precipitation averages for large areas. Climatological data for July, 1911, Monthly Weather Review, 1082-1084

TorRe A., GILly J.P., 2000. On the Analytical Dimension of Proximity Dynamics, Regional Studies, 34(2), 169-180

URSULICA T.E., 2016. The relationship between health care needs and accessibility to health care services in Botosani county- Romania, Procedia Environmental Sciences, 32, 300-310

Vlădescu C., ScînTee S.G., Olsavszky V., HernándeZ-Quevedo C., SAGAN A., 2016. Health systems in transition: Romania: health system review in Health systems in transition, 18(4)

YAMADA I., 2016. Thiessen polygons in The International Encyclopedia of Geography, Edited by Douglas Richardson (Ed.). John Wiley \& Sons, Ltd., 350-359 